
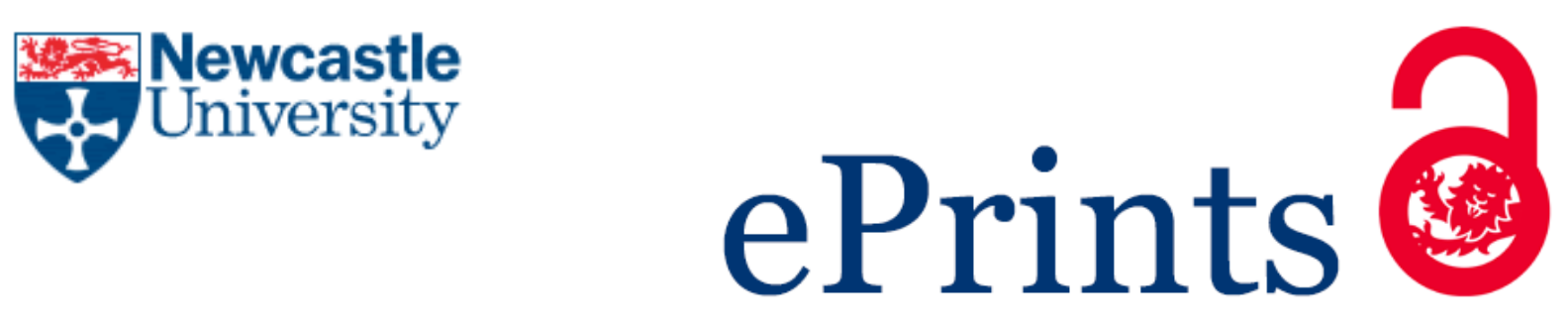

Pathare PB, Berry TM, Opara UL.

Changes in moisture content and compression strength during storage of ventilated corrugated packaging used for handling apples.

Packaging Research 2016, 1(1), 1-6

\title{
Copyright:
}

(C) 2016 P. B. Pathare et al., published by De Gruyter Open. This work is licensed under the Creative Commons Attribution-NonCommercial-NoDerivs 3.0 License.

DOI link to article:

http://dx.doi.org/10.1515/pacres-2016-0001

Date deposited:

$22 / 06 / 2016$

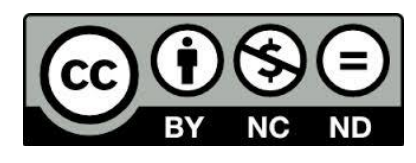

This work is licensed under a

Creative Commons Attribution-NonCommercial-NoDerivatives 4.0 International licence 
Pankaj B. Pathare, Tarl M. Berry, and Umezuruike Linus Opara*

\section{Changes in moisture content and compression strength during storage of ventilated corrugated packaging used for handling apples}

DOI 10.1515/pacres-2016-0001

Received Feb 19, 2016; accepted Jun 07, 2016

\begin{abstract}
This study investigated the effects of cold storage $\left(-0.5^{\circ} \mathrm{C}\right.$ at $\left.90 \% \mathrm{RH}\right)$ on the mechanical performance of 'MK4' ventilated packaging used for handling pome fruit. The packages were stored over a period of 43 days. Compression strength of packages was measured by Lansmont squeezer compression testing machine on day 2, 4, 6 and 8 and then weekly over 6 weeks. The effect of storage duration on package moisture content and compression strength was also examined. Maximum compressive strength was reduced from 7351 to $3872 \mathrm{~N}$ after 2 days of storage. The package compressive strength decreased with an increase in moisture content. Average compression strength was observed to decrease by $618 \mathrm{~N}$ per one percent increase in moisture content. Pseudo first order kinetic model could satisfactorily analyse the adsorption of water by corrugated package with coefficient of determination of 0.9816 and standard error of 0.2554 . Relationship between package compression strength with change in moisture during storage showed good correlation.
\end{abstract}

Keywords: Corrugated packaging; Compression strength; Vent area; Moisture content

Pankaj B. Pathare: Postharvest Technology Research Laboratory, South African Research Chair in Postharvest Technology, Department of Horticultural Sciences, Faculty of AgriSciences, Stellenbosch University, South Africa; Postharvest Technology Research Laboratory, South African Research Chair in Postharvest Technology, Department of Food Science, Faculty of AgriSciences, Stellenbosch University, South Africa; Email: pbpathare@gmail.com Tarl M. Berry: Postharvest Technology Research Laboratory, South African Research Chair in Postharvest Technology, Department of Horticultural Sciences, Faculty of AgriSciences, Stellenbosch University, South Africa

${ }^{\star}$ Corresponding Author: Umezuruike Linus Opara: Postharvest Technology Research Laboratory, South African Research Chair in Postharvest Technology, Department of Horticultural Sciences, Faculty of AgriSciences, Stellenbosch University, South Africa; Postharvest Technology Research Laboratory, South African Research Chair in Postharvest Technology, Department of Food Sci-

\section{Introduction}

Packaging is one of the most important steps in the long and complicated journey of fresh horticultural produce from grower to consumer. Venting, which is necessary for precooling and proper air circulation, also has the effect of decreasing mechanical strength of the package. Corrugated paperboard strength is an important requirement to protect produce against damage during storage and transport $[1,2]$. The structural performance of a corrugated package is an important shipping requirement and has changed the paperboard market from one based on tonnage to one based on performance [3]. Box compression strength (BCT) commonly measure the performance potential of a corrugated board package [4].

Many researchers reported that corrugated paperboard is sensitive to the environmental conditions, such as high relative humidity [5-9]. Mechanical properties of corrugated paperboard are susceptible to temperature and relative humidity variation during the manufacturing, storage and distribution [10] Compression strength of a corrugated package in a given environment depends on the moisture content due to hysteresis in the absorption/desorption curve [11]. The increase in moisture content in the material breaks the bonds between cellulose fibres, affecting the mechanical behaviour and leading to subsequent failure load of the material [5]. Wetness due to high humidity storage reduces the compression strength of corrugated paperboard packaging. The strength reduction can lead to packaging collapse and mechanical damage to produce [12]. Furthermore, wetting of the cardboard may lead to biodeterioration of the package [13]. Box strength requirement and the influence of environmental exposure on the package performance must be considered when designing corrugated package for long term storage of fresh horticultural produce [14].

ence, Faculty of AgriSciences, Stellenbosch University, South Africa; Email: opara@sun.ac.za; umunam@yahoo.co.uk 


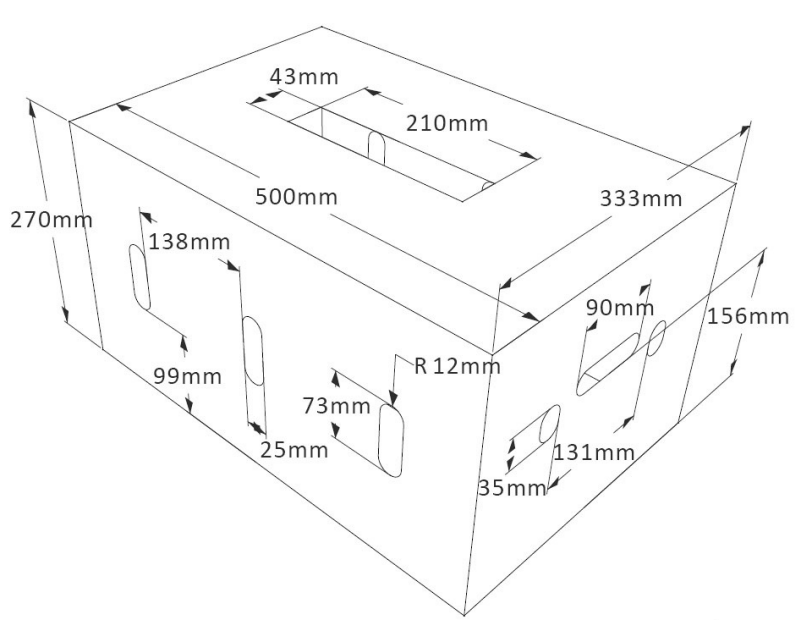

Figure 1: Ventilated corrugated packaging design (MK4) studied.

Fresh horticultural produce is subject to palletizing, cold storage and transportation, and hence the package must exhibit high stacking strength, resistance to moisture and withstand frequent changes in humidity [15]. Low temperature and high humidity are recommended to maintain quality of fresh horticultural produce [16]. Corrugated boxes stored under high humidity environments reduce their strength after absorbing moisture. Moisture is especially important when loading occurs over long periods as corrugated packaging sometimes fails during transportation and storage. Ventilated corrugated package should be designed to withstand mechanical stresses during distribution process. For engineering purposes, therefore, it is important to be able to determine the allowable load that does not cause collapse within the foreseen storage time. A number of researchers have studied airflow as well as the heat and mass transfer characteristics of ventilated packing systems [17-21], however very limited studies were found on package compression strength of ventilated corrugated packaging. In this study, the mechanical strength of 'MK4' corrugated packaging designs used in the pome fruit industry was investigated under compression load at storage conditions $\left(-0.5^{\circ} \mathrm{C}\right.$ at $\left.90 \% \mathrm{RH}\right)$. Effect of storage conditions on moisture content of package was also studied.

\section{Materials and methods}

Ventilated corrugated package, 'MK4', was used in this study (Figure 1). The package had dimensions of 500 (L) $\times 333(\mathrm{~W}) \times 270(\mathrm{H}) \mathrm{mm}$ and carrying capacity of $18 \mathrm{~kg}$. The corrugated paperboard for MK4 is a single wall of type ' $\mathrm{C}$ ' flute. The corrugated paperboard used is made from Kraft paper with a paper grammage of $250 \mathrm{gm}^{-2}$ for both inner and outer liners and a paper grammage of $175 \mathrm{gm}^{-2}$ for the flute (corrugated medium). The package has open areas along the length and width, which were $3.8 \%$ and $3.5 \%$, respectively, while both the top and bottom sections had vent areas of 5.4\%.

'MK4' package design was conditioned at $23 \pm 1^{\circ} \mathrm{C}$ and $50 \%$ relative humidity for 48 hours prior to testing in accordance with ASTM D4332. The packages were stored under the storage condition temperatures $\left(-0.5^{\circ} \mathrm{C}\right.$ and $90 \%$ $\mathrm{RH})$ over a period of 43 days. Compression strength of packages was first measured on days 2, 4, 6 and 8 and then weekly over 6 weeks. All compression tests were conducted using a Lansmont squeezer compression test system (Lansmont Corporation, Monterey, CA, USA). A preload of $222.2 \mathrm{~N}$ was applied prior to observing the compression strength values. The floating-platen mode of the compression tester was used to conduct all testing at a speed of $12.7 \pm 2.5 \mathrm{~mm} / \mathrm{min}$ until failure was observed. Box compression test (BCT) is a pure top-to-bottom compression load test between flat parallel steel plates that is carried out on an empty sealed corrugated board box using a constant deformation speed [22]. The compressive load and crosshead displacement are recorded continuously until collapse occurs. Five different boxes were tested and the average values used for calculations. The moisture content was determined by the method of oven drying at temperature of $105^{\circ} \mathrm{C}$ (TAPPI T412) to constant weight.

Data analysis was performed using Microsoft Windows Excel 2007 and SAS 9.2 software (SAS, North Carolina, USA). Bonferroni comparisons were completed on the replicated data $(\alpha=0.05)$ in all tests.

\section{Result and discussion}

\subsection{Variation in moisture content and strength with storage duration}

Average moisture content at $23^{\circ} \mathrm{C}$ and $50 \% \mathrm{RH}$ is $5.05 \%$ $\mathrm{db}$ (g water/g dry matter) for MK4 packaging. The moisture content of MK4 package exposed to storage condition $\left(-0.5^{\circ} \mathrm{C}\right.$ and $\left.90 \% \mathrm{RH}\right)$ over a storage period of 43 days is shown in Figure 2. Storage period from day 2 to 43 days showed the non significant effect $(\mathrm{P}<0.05)$ on moisture content for 'MK4' packages. During that time, the moisture content increased by $61-118 \%$ compared to standard ASTM storage condition. Corrugated package 


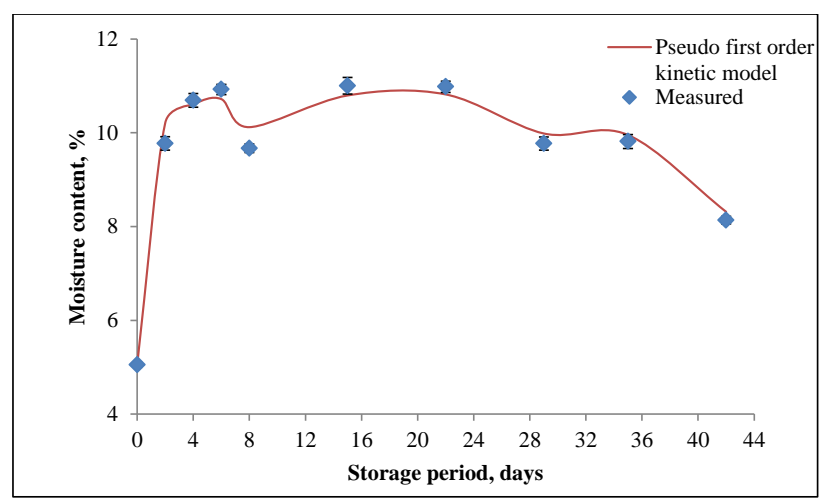

Figure 2: Moisture content of the corrugated package. Solid lines are fitted values. Bars represent standard error of the means $(n=5)$.

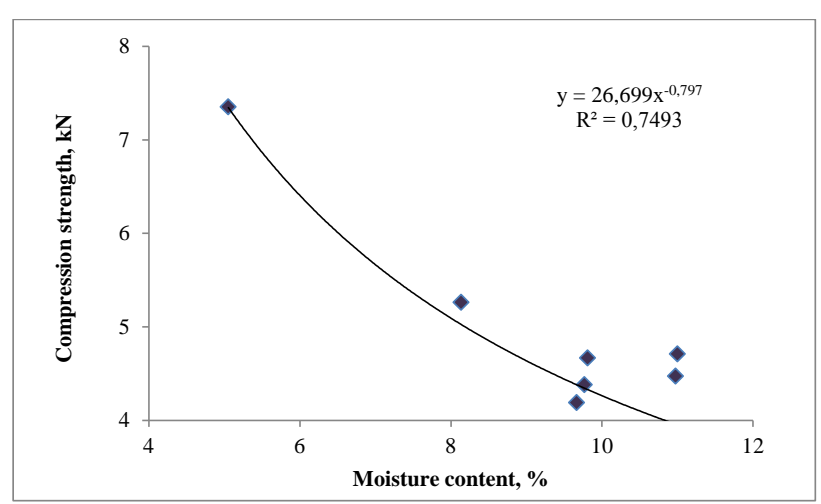

Figure 3: Relationship between moisture content and maximum compressive strength of corrugated package. Solid curves are fitted values $(n=5)$.

adsorbed water and moisture content increased with high humidity storage.

Pseudo first order kinetic model was used to analyse the adsorption of water by corrugated package. This equation has been used for water adsorption of brown rice [23], corrugated cardboard [6].

$$
\frac{d M}{d t}=k_{1}\left(M_{e}-M\right)
$$

where $k_{1}$ is the rate constant of pseudo first-order adsorption $\left(\right.$ day $^{-1}$ ) calculated as 0.0192 , and $M_{e}$ and $M$ are the moisture content (\%db) at equilibrium and at time $t$ (day). The method described by Jain and Pathare [24] was used to determine the equilibrium moisture content. After definite integration by applying the initial conditions $(t=0$, $M=M_{o}$ ), Eq. (1) becomes

$$
M=M_{e}+\left(M_{0}-M_{e}\right) \exp \left(-k_{1} t\right)
$$

where $M_{o}$ is the initial moisture content. The result in Figure 2 presents moisture content of corrugated package exposed to storage condition. Water absorption increased with time until it reached saturation. The data obtained from the pseudo first-order Eq. (2) was represented by a solid line. These expressions can be used to estimate the moisture content at any time with respect to the storage days with the greater accuracy. The established model was validated with experimental values of moisture content for all the tests of experiment. The linear regression of these results gave the following expression as

$$
\begin{gathered}
M_{\text {pre }}=0.9681 M_{\text {exp }}+0.3821 \\
\left(\mathrm{R}^{2}=0.9816, \mathrm{e}_{s}=0.2554\right)
\end{gathered}
$$

where $M$,pre and $M$,exp are the predicted and measured moisture content of corrugated package, respectively.

Eq. (4) represented the relationship between moisture content and maximum compressive strength [6] is as

$$
F=a M^{b}
$$

where $F$ is compressive strength $(\mathrm{kN})$ and the constant calculated as $a=26.699, b=-0.797$. Maximum compressive strength of corrugated package was strongly dependent upon the moisture content (Figure 3). The maximum compressive strength of corrugated package was predicted using Eq. (5) which was obtained from Eqs. (2-4).

$$
F=a\left[M_{e}+\left(M_{0}-M_{e}\right) \exp \left(-k_{1} t\right)\right]^{b}
$$

Eq. (6) can be used to estimate the compression strength of package at any time with respect to the storage days with the greater accuracy.

$$
\begin{array}{r}
F_{p r e}=0.8466 F_{\text {expt }}+0.6474 \\
\left(\mathrm{R}^{2}=0.8519, \mathrm{e}_{s}=0.4553\right)
\end{array}
$$

where $F_{\text {pre }}$ and $F_{\text {exp }}$ are the predicted and measured compression strength of corrugated package, respectively.

\subsection{Effect of storage duration on package strength}

Storage duration has the influence on package compression strength. Mean compression strength of 'MK4' package designs at storage condition is shown in Figure 4. 'MK4' packaging shows the highest compression strength $(7351 \mathrm{~N})$ at standard testing condition. Figure 5 compared the compressive strength of 'MK4' packages exposed to storage conditions for 43 days. It showed the strength reduction between 28 to $53 \%$ at different storage periods. The packaging strength reduces from 7351 to $3872 \mathrm{~N}$ after 2 day 


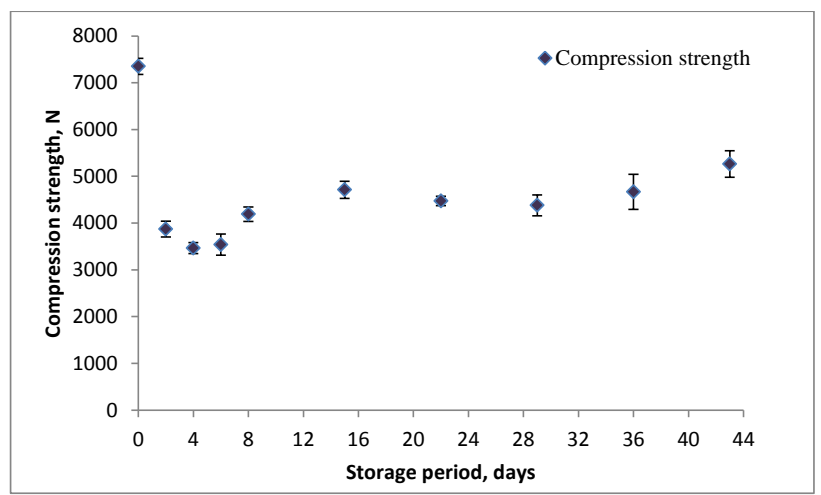

Figure 4: Mean compression strength of package during cold storage $\left(-0.5^{\circ} \mathrm{C}\right.$ and $\left.90 \% \mathrm{RH}\right)$.

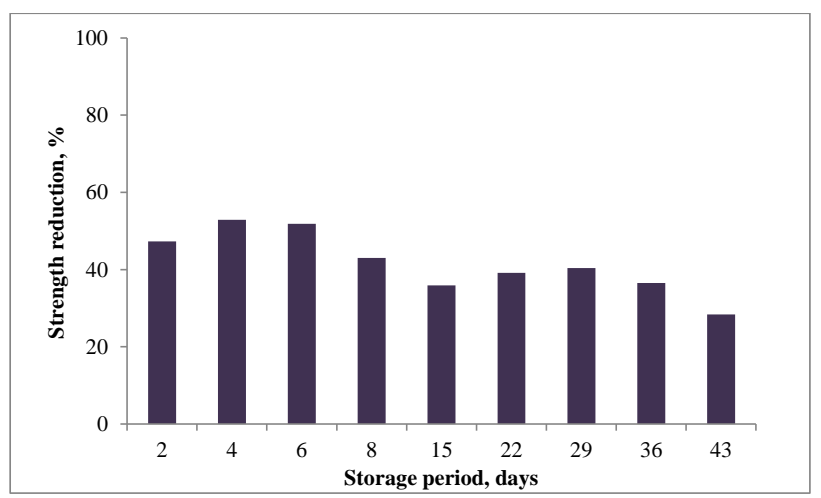

Figure 5: Package compression strength retained at storage condition $\left(-0.5^{\circ} \mathrm{C}\right.$ and $\left.90 \% \mathrm{RH}\right)$ compared to testing under standard (ASTM) condition $\left(23^{\circ} \mathrm{C}\right.$ and $\left.50 \% \mathrm{RH}\right)$.

storage period. However packaging strength changed from 3464.2 to $5261.9 \mathrm{~N}$ during from day 4 to 43 days.

Mean compressive strength of MK4 package exposed to storage condition $\left(-0.5^{\circ} \mathrm{C}\right.$ and $\left.90 \% \mathrm{RH}\right)$ decreased gradually over the time. From our experiments the moisture content of the package increased to $11 \%$ and maintained its maximum compressive load at $64.1 \%$ of 'MK4' package. After 43 days storage the package showed moisture content $8.14 \%$ and its maximum compressive strength reduced to $28.4 \%$. BCT is a function of moisture content as compression strength distinctly decreases with the ascending of moisture content. Twede and Selke [7] reported that a box had lost its compression strength by about $40 \%$ at $85 \%$ RH. As the RH increased to $90 \%$, the box was lost nearly $50 \%$ of its compression strength. Evidence was shown from our experiments that when the package was exposed to $90 \%$ humidity, the moisture content of the board remained at approximately $8.14 \%$ and maintained its maximum compressive load at $71.6 \%$ after 43 days.

Maximum strength reduction was found for the 2 day storage period ( $1739.1 \mathrm{~N} /$ day). After 2 days of storage, the moisture content of the package increased to $9.77 \%$ and maintained its maximum compressive strength at $52.7 \%$. As corrugated package moisture content increased from $7.7 \%$ to $16.4 \%$, compressive strength reduced by $52 \%$ [25]. Storage condition from standard testing to cold storage (day 2) shows significant influence on package compression strength $(P<0.05)$. However, the effect of storage period at day 2 to day 43 on compression strength was non significant. The influence of moisture content should be concerned when predicting the strength of corrugated packaging. The main impact of package design on optimisation of the fresh produce is to maintain mechanical integrity and improve cooling performance. An optimal package design with respect to mechanical integrity is not necessarily the best with respect to cooling performance and fruit quality.

Average compression strength decreased $618 \mathrm{~N}$ per moisture content percent from standard storage condition to $-0.5^{\circ} \mathrm{C}$ and $95 \%$ RH storage. However maximum compression strength $(737 \mathrm{~N})$ decrease per moisture content was for early two day storage. As the increasing moisture content of the components have softened the lignin matrix between the cellulose microfibrils of the wood fibres and affects its mechanical property [1]. Moisture content of package during storage period (day 2 to 43) had non significant influence on package compression strength $(P<$ 0.05). Average 'MK4' package had lost $8.4 \%$ strength per moisture content throughout the storage period. Typically a $1 \%$ change in moisture causes a $7 \%$ to $10 \%$ reduction in strength [11].

\subsection{Effect on package deformation}

Package deformation is a measure of how much a box is compressed at the end of a compression test [22]. Compression strength values of packages commonly include the deflection at failure or at the end of a specific load application. Under compression testing corrugated packaging displays buckling after deformation. Package deformation under storage period is shown in Figure 6. 'MK4' package designs showed the deformation $1.28 \mathrm{~cm}$ for maximum compression strength at standard ASTM testing. Storage duration had non significant influence on package deformation $(P<0.05)$. In the range of $8-11 \%$ moisture content of the packages tested under the investigated storage conditions, the displacement was in the range of 1.28 to $1.41 \mathrm{~cm}$. In the current work, the displacement was not significantly $(P<0.05)$ affected by the moisture content of the package (Figure 7). This finding is in agreement with Paunonen and Gregersen [26] who studied the effect of 


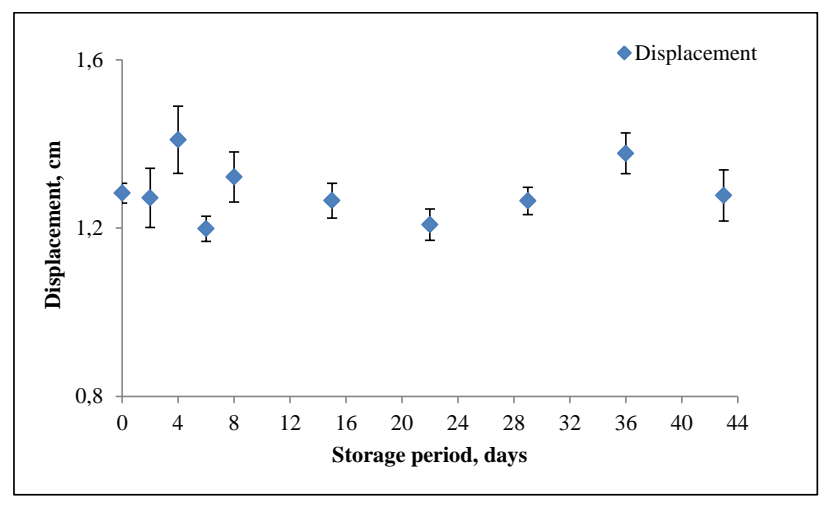

Figure 6: Changes in displacement of packaging at maximum compression strength during cold storage $\left(-0.5^{\circ} \mathrm{C}\right.$ and $\left.90 \% \mathrm{RH}\right)$.

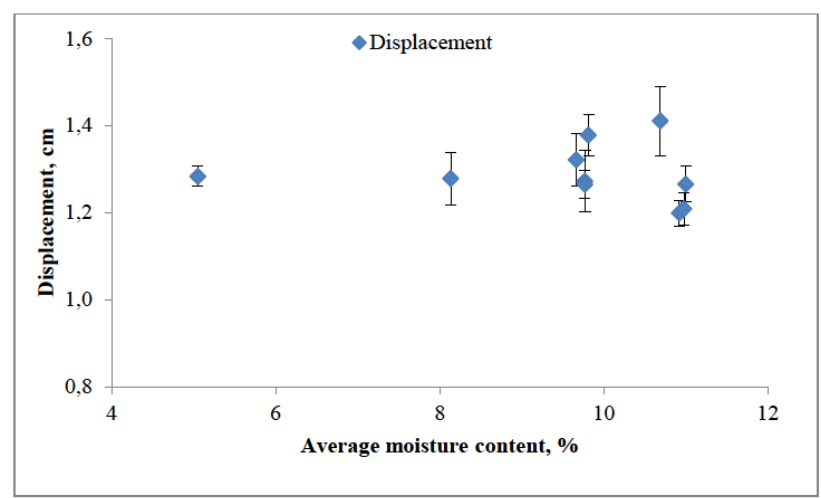

Figure 7: Effect of moisture content on displacement of packaging at maximum compression strength.

moisture content (range of $2 \%-11 \%$ ) on deformation and found that the displacement was constant $(10 \mathrm{~mm})$. The authors concluded that failure criterion for corrugated packaging in compression can be based on vertical displacement, and this is independent of moisture content.

\section{Conclusions}

In this investigation, the effects of storage duration on the moisture content and compression strength of 'MK4' package design used in the pome fruit industry were investigated. Pseudo first order kinetic model was used to predict the moisture content of package during storage period, providing a reasonable approximation. Package compression strength reduced with increase in moisture content. Maximum compression strength was reduced by $47.3 \%$ after 2 day storage. Maximum deformation did not depend on moisture content of the packaging material. This research can be of great help to corrugated packaging de- signers and handlers of various types of fresh horticultural produce at cold storage and transportation to preserve the strength of corrugated package, thereby ensuring a good quality product to the final consumers.

Acknowledgement: This work is based upon research supported by the South African Research Chairs Initiative of the Department of Science and Technology and National Research Foundation. The financial support of the South African Postharvest Innovation Programme (PHI-2) and Hortgro ${ }^{\text {Science }}$ through the award of a project on "Packaging of the Future" is gratefully acknowledged.

\section{References}

[1] Navaranjan N, Dickson A, Paltakari J, Ilmonen K. Humidity effect on compressive deformation and failure of recycled and virgin layered corrugated paperboard structures. Composites Part B: Engineering. 2013; 45:965-71.

[2] Biancolini M, Brutti C, Porziani S. Corrugated board containers design methods. International Journal of Computational Materials Science and Surface Engineering. 2010; 3:143-63.

[3] Luo S, Suhling J, Laufenberg T. Bending and twisting tests for measurement of the stiffnesses of corrugated board. ASME Applied Mechanics Division Publications-AMD. 1995; 209:91-.

[4] Markström H. Testing Methods and Instruments for Corrugated Board. Ostervala: Lorentzen \& Wettre; 1999.

[5] Allaoui S, Aboura Z, Benzeggagh M. Phenomena governing uniaxial tensile behaviour of paperboard and corrugated cardboard. Composite Structures. 2009; 87:80-92.

[6] Hung DV, Nakano Y, Tanaka F, Hamanaka D, Uchino T. Preserving the strength of corrugated cardboard under high humidity condition using nano-sized mists. Composites Science and Technology. 2010; 70:2123-7.

[7] Twede D, Selke SE. Cartons, Crates and Corrugated Board: Handbook of Paper and Wood Packaging Technology. Lancaster: DEStech Publications; 2005.

[8] Hägglund R, Carlsson L. Packaging performance. In: Niskanen K, editor. Mechanics of Paper Products. Berlin: De Gruyter; 2011.

[9] Pathare PB, Opara UL. Structural design of corrugated boxes for horticultural produce: A review. Biosystems Engineering. 2014; 125:128-40.

[10] Dongmei W, Huxiang G, Ziyou B. Effect investigation of relative humidity and temperature on multi-layer corrugated sandwich structures. Journal of Sandwich Structures and Materials. 2013; 15:156-67.

[11] Frank B. Corrugated box compression--A literature survey. Packaging Technology and Science. 2014; 27:105-28.

[12] Marcondes J. Cushioning properties of corrugated fiberboard and the effects of moisture content. Transactions of the ASAE. 1992; 35:1949-53.

[13] Koivula N, Hänninen K. Biodeterioration of cardboard-based liquid containers collected for fibre reuse. Chemosphere. 1999; 38:1873-87. 
[14] Koning Jr J, Stern R. Long-term creep in corrugated fiberboard containers. Tappi Journal. 1977; 60:128-31.

[15] Patterson J. Material reduction in corrugated containers for the fresh produce industry. Project report, Industrial Technology, Orfalea College of Business, USA; 2011.

[16] Uchino T, Tanaka F, Hamanaka D, Nakano Y. Moisture content and strength of corrugated cardboard exposed to a nano-sized mist. International Symposium Postharvest Pacifica 2009Pathways to Quality: V International Symposium on Managing Quality in 8802009. p. 533-7.

[17] Ngcobo ME, Delele MA, Opara UL, Zietsman CJ, Meyer CJ. Resistance to airflow and cooling patterns through multi-scale packaging of table grapes. International Journal of Refrigeration. 2012; 35:445-52.

[18] Delele MA, Ngcobo MEK, Getahun ST, Chen L, Mellmann J, Opara UL. Studying airflow and heat transfer characteristics of a horticultural produce packaging system using a 3-D CFD model. Part I: Model development and validation. Postharvest Biology and Technology. 2013; 86:536-45.

[19] Defraeye T, Lambrecht R, Tsige AA, Delele MA, Opara UL, Cronjé $P$, et al. Forced-convective cooling of citrus fruit: Package design. Journal of Food Engineering. 2013; 118:8-18.

[20] Zou Q, Opara LU, McKibbin R. A CFD modeling system for airflow and heat transfer in ventilated packaging for fresh foods: I. Initial analysis and development of mathematical models. Journal of Food Engineering. 2006; 77:1037-47.
[21] Vigneault C, Castro (de) LR. Produce-simulator property evaluation for indirect airflow distribution measurement through horticultural crop package. Journal of Food, Agriculture and Environment. 2005; 3:93-8.

[22] Singh J, Olsen E, Singh SP, Manley J, Wallace F. The effect of ventilation and hand holes on loss of compression strength in corrugated boxes. Journal of Applied Packaging Research. 2008; 2:227-38.

[23] Genkawa T, Uchino T, Miyamoto S, Inoue A, Ide Y, Tanaka F, et al. Development of mathematical model for simulating moisture content during the re-wetting of brown rice stored in film packaging. Biosystems Engineering. 2008; 101:445-51.

[24] Jain D, Pathare PB. Selection and evaluation of thin layer drying models for infrared radiative and convective drying of onion slices. Biosystems Engineering. 2004; 89:289-96.

[25] Zhang Y-I, Chen J, Wu Y. Analysis on hazard factors of the use of corrugated carton in packaging low-temperature yogurt during logistics. Procedia Environmental Sciences. 2011; 10:968-73.

[26] Paunonen S, Gregersen $\emptyset$. The effect of moisture content on compression strength of boxes made of solid fiberboard with polyethylene coating. Journal of Applied Packaging Research. 2010; 4:223-42. 